\title{
Relações entre Estado e associações: origens de associações ambientais em Santos (SP).
}

\section{Relationship between State and associations: evidence on associations working in the environmental área in Santos (SP).}

\author{
Olivia Cristina Perez
}

Resumo: A pesquisa verificou a relação entre associações ambientais e Estado, especificamente os motivos envolvidos na criação de associações, segundo os sujeitos envolvidos nesse processo. Partiu-se da corrente teórica chamada de democracia associativa, que considera as associações como artefatos, na medida em que são produtos de estruturas econômicas e políticas. Foram levantados dados sobre o perfil e o financiamento das fundações privadas e associações sem fins lucrativos no Brasil. Também foram feitas entrevistas com membros das onze associações que trabalham em prol do meio ambiente no município de Santos, litoral do estado de São Paulo, entre os anos de 2015 e 2016. Os resultados demonstram que as associações surgem em sua maioria no início dos anos 2000 em um contexto de forte financiamento estatal para as mesmas.

Palavras-Chave: Democracia Associativa; Associações; Associações

Socioambientais.

Abstract: The research verified the relationship between associations working in the environmental área and the State, specifically the reasons involved in the creation of associations, according to the subjects involved in this process. The research started from the theoretical framework called associative democracy that understands associations as artifacts, insofar as they are products of economic structures and policies. Data were collected on the profile and financing of private

\footnotetext{
* Doutora em Ciência Política pela Universidade de São Paulo (FFLCH/USP). É mestre em Sociologia, também pela Universidade de São Paulo. Cursou o bacharelado e licenciatura plena em Ciências Sociais na Universidade Estadual Paulista (FCLAr/UNESP). Atualmente é Professora Adjunta na Universidade Federal do Piauí (UFPI) vinculada aos cursos de bacharelado e mestrado em Ciência Política e ao programa de pós-graduação (mestrado e doutorado) em Políticas Públicas. Coordena o programa de Pós-Graduação em Ciência Política da UFPI. É Editora Associada da Revista Brasileira de Ciências Sociais (RBCS/Anpocs) na área de Ciência Política. Faz parte da Associação Brasileira de Ciência Política (ABCP) como presidente da regional Nordeste.
} 
foundations and non profit associations in Brazil. Interviews were also conducted with members of the eleven associations that work for the environment in the municipality of Santos, on the coast of the state of São Paulo, between the years 2015 and 2016. The results show that the associations appear mostly in the early years 2000 in a context of strong state funding.

Keywords: Associative Democracy; Associations; Socio-environmental Associations.

\section{INTRODUÇÃO}

Esta pesquisa examina relações entre associações e Estado, com foco nos motivos que levam à criação de associações ambientais. É marcante a presença de associações no Brasil. Conforme o Mapa das Organizações da Sociedade Civil, em 2016, existiam 820.186 associações no país (IPEA, 2017). Na área ambiental, conforme o levantamento feito pelo Instituto Brasileiro de Geografia e Estatística (IBGE, 2012) foram criadas 1.349 novas associações entre os anos de 2001 a 2010. Essas associações auxiliam as empresas privadas, cobram do governo o respeito e ampliação das leis na área e atuam em projetos ambientais.

Frente ao crescimento das associações em geral, particularmente daquelas que têm o meio-ambiente como escopo, a presente pesquisa foi guiada pelas seguintes questões: por que tais associações são formadas? Como as decisões políticas e econômicas são levadas em consideração pelos atores que criam as associações? A pesquisa responde essas questões com base na suposição de que as associações na área ambiental surgem devido ao incentivo ofertado pelo Estado principalmente financiando o trabalho das mesmas. Orientado pela ideia de que as decisões políticas influenciam na conformação das associações, o objetivo deste estudo foi verificar os motivos envolvidos na criação de associações na área ambiental, segundo os sujeitos envolvidos nesse processo que foram entrevistados entre os anos de 2015 e 2016 e que relataram que o crescimento das associações em que trabalham ocorreu no início dos anos 2000. 
Embora a reflexão sobre as associações remeta à obra clássica de Tocqueville A democracia na América Latina ([1835] 2005), estudos recentes (LAVALLE; SWAKO, 2015; LÜCHMANN; SCHAEFER; NICOLETTI, 2017) indicam um retorno do interesse sobre o tema. Em geral, tem-se destacado o crescimento das associações (LÜCHMANN; ALMEIDA; TABORDA, 2019), a pluralidade delas (LÜCHMANN, 2014; LÜCHMANN; SCHAEFER; NICOLETTI, 2017), bem como a diversidade de relações entre as associações e o Estado e seus potencias (ABERS; SERAFIM; TATAGIBA, 2014; CARLOS; DOWBOR; ALBUQUERQUE, 2017; COSTA, 2017; LAVALLE; SWAKO, 2015; MENDONÇA, MEDEIROS; ARAÚJO, 2019; PISMEL, 2019).

$\mathrm{Na}$ área ambiental, estudos que examinam as relações entre Estado e associações mostram como os movimentos sociais se dedicaram a reivindicar a criação de órgãos governamentais, apoiaram candidaturas dentro de partidos já consolidados e contribuíram para a criação de um partido político: o Partido Verde (PV) (ALONSO; COSTA; MACIEL, 2007). Por outro lado, o Estado é central no trabalho das associações ao financiá-las (FOSSALUZA; TOZONI-REIS, 2015).

A literatura também fornece explicações sobre o surgimento das associações no Brasil, ainda que tais argumentos não sejam explícitos. Em geral os trabalhos atribuem o crescimento das associações à efervescência da sociedade civil nas campanhas pela democracia (SADER, 1988; DOIMO, 1995), ou devido aos incentivos promovidos pelo governo de Fernando Henrique Cardoso (BRESSER PEREIRA; GRAU, 1999; CARDOSO, 1997; DAGNINO, 2004; FERNANDES, 1994; MONTAÑO, 2002; SADER, 2002), e ainda pela aposta do governo federal do Partido dos Trabalhadores (PT) nas Instituições de Participação (ARAÚJO, 2014; AVRITZER, 2016; NOGUEIRA, 2013; OLIVEIRA, 2016; POGREBINSCHI, 2012) e no ativismo estatal (ABERS; SERAFIM; TATAGIBA, 2014; ABERS; VON BÜLOW, 2011; GURZA LAVALLE; CARLOS; DOWBOR; SZWAKO, 2019; CAYRES, 2017; PIRES; VAZ, 2014).

A presente pesquisa se diferencia dessa literatura ao se concentrar na influência da orientação estatal sobre a decisão dos ativistas em formar uma associação. Para essa reflexão, são retomados trabalhos sobre a democracia associativa que demostram que tanto as associações contribuem para a democracia, 
como determinados tipos de regras estatais influenciam sua conformação (BADER, 2001; COHEN; ROGERS, 1995; FUNG, 2003; HIRST, 2001; WARREN, 2001). Tais autores são ainda pouco utilizados no Brasil, com exceção dos trabalhos de Lüchmann (LÜCHMANN, 2012, 2014; LÜCHMANN; ALMEIDA; TABORDA, 2019; LÜCHMANN; SCHAEFER; NICOLETTI, 2017).

Trata-se de uma pesquisa descritiva que utiliza dados quantitativos obtidos de institutos de pesquisas e informações qualitativas provenientes de pesquisa de campo. Para demonstrar e contextualizar os períodos de crescimento das associações no Brasil, foram sistematizadas informações acerca das fundações privadas e associações sem fins lucrativos (Fasfil) no Brasil e em Santos, disponibilizadas pelo IBGE (2012) e pelo Instituto de Pesquisa Econômica Aplicada (IPEA, 2017). Também foram retomados dados de pesquisas que descrevem a dinâmica do financiamento estatal para as entidades sem fins lucrativos no Brasil (Ipea, 2011) bem como textos do Instituto de Pesquisa Econômica Aplicada sobre investimentos nas associações (LOPEZ, 2018; LOPEZ; BUENO, 2012; MELLO; PEREIRA; ANDRADE, 2019).

Os dados indicaram crescimento das associações a partir dos anos de 1970 até meados de 2010. No entanto, tais dados não são fontes de explicação do fenômeno. A relação entre financiamento estatal e crescimento das associações foi analisada a partir de entrevistas qualitativas com fundadores de todas as associações ambientais sediadas no município de Santos, localizado no litoral do estado de São Paulo.

Os dados do IBGE (2012) mostraram que a maior parte das associações no Brasil e em Santos são religiosas. O meio ambiente e causa animal é o que contava com o menor número de associações em Santos (apenas cinco). ${ }^{1}$ Esse foi um dos fatores que levou à escolha da área ambiental: o baixo número de associações permitiu entrevistas com todas elas.

A escolha da cidade de Santos se justifica pelo fato de que o Sudeste é a região que mais concentra organizações da sociedade civil, com destaque para São Paulo,

\footnotetext{
${ }^{1}$ A pesquisa do IBGE (2012) intitulada Fundações Privadas e Associações Sem Fins Lucrativos no Brasil (FASFIL) reúne na mesma categoria as associações voltadas ao meio ambiente e proteção animal. No entanto, não se trata do mesmo escopo. $\mathrm{O}$ foco do texto são as associações ambientais.
} 
que contava em 2017 com 394.900 organizações (Ipea, 2017). As associações ambientalistas são encontradas em todo o estado de São Paulo, com maior concentração na capital e nas cidades litorâneas (FOSSALUZA; TOZONI-REIS, 2015). Esse é o caso de Santos, que sedia diversas associações sem fins lucrativos trabalhando em prol da questão ambiental.

Ademais, a cidade apresenta diversos problemas socioambientais, muitos ligados ao Porto de Santos, o maior e mais importante complexo portuário da América do Sul. Por exemplo, na região portuária ocorreram graves acidentes: em abril de 2015 cinco tanques de produtos químicos pegaram fogo durante nove dias; em janeiro de 2016 um vazamento de gás dentro do complexo do Porto liberou uma nuvem tóxica em Santos e em outras cidades do litoral de São Paulo (FOLHA DE S. PAULO, 2015, 2016).

Selecionar uma região com problemas, acidentes socioambientais e forte presença de associações possibilita cogitar se haveria uma relação entre esses fenômenos - como o fato de as associações terem sido criadas por conta dos acidentes e problemas ambientais -, ou se então existiriam outras explicações.

$\mathrm{Na}$ pesquisa de campo, primeiramente foram localizadas as associações da área socioambiental em seus espaços de participação - especialmente o Conselho Municipal de Meio Ambiente. Também foi solicitada junto à prefeitura a lista de todas as organizações da área. Após essa sondagem inicial oito organizações foram localizadas. Para complementar tais informações, os entrevistados eram solicitados a indicar o nome de outras organizações que trabalhavam na área e assim sucessivamente, de modo a gerar novas rodadas de entrevistas. Ao todo foram localizadas onze associações. Os fundadores de todas elas foram entrevistados no fim do segundo semestre do ano de 2015 e no começo de 2016. As entrevistas partiram de um roteiro semiestruturado que versava sobre a atuação das associações santistas e percepções acerca de suas origens.

Para manter o sigilo combinado com os entrevistados, optou-se pela identificação das associações por meio de letras. As atividades das associações eram diversificadas, embora seja possível estabelecer um escopo central, geralmente ligado à preservação da fauna e à limpeza de praias e mangues; trabalhos ademais bastante parecidos. O consumo de água, produção, limpeza e reciclagem de lixo são 
o foco de cinco associações (B, C, H, I e J), enquanto outras cinco (associações D, E, F, G e K) se dedicam à preservação da fauna marinha e da região costeira. Apenas a associação A difere das demais por ofertar oficinas e atendimentos voltados à população residente em uma região de mangue e em situação de vulnerabilidade social.

O conteúdo das entrevistas foi analisado com a intenção de apreender concepções em comum sobre as origens das associações. A análise de conteúdo é uma técnica bastante utilizada nas pesquisas qualitativas, uma vez que seu principal objetivo consiste em verificar a frequência em que ocorrem determinadas construções em um texto, o que permite sistematizar as entrevistas realizadas (Bardin, 2006).

O estudo contribui com a área de conhecimento sobre as associações, principalmente por analisar a relação entre Estado e associações a partir da democracia associativa - referencial teórico ainda pouco utilizado no Brasil. Partindo desse referencial teórico, o estudo avança ao se concentrar na influência das decisões estatais sobre as associações, superando uma visão dicotômica a respeito dessas esferas e seguindo em direção diversa à da literatura que analisa o impacto dos movimentos sociais sobre as políticas públicas.

\section{Relações entre associações e estado}

A democracia associativa aposta nas associações para aprimorar a democracia (BADER, 2001; COHEN; ROGERS, 1995; FUNG, 2003; HIRST, 2001; WARREN, 2001). Tal literatura, bastante presente nos Estados Unidos, tem influência de Tocqueville - famoso por examinar o papel das associações na democracia norteamericana.

As associações, entendidas como mediações sociais, são divididas por Warren (2001) em três tipos, conforme a natureza dos laços e grau de autonomia das mesmas: associações primárias - famílias e amizades que formam redes com relações próximas e íntimas; associações secundárias - transcendem o mundo individual, como os grupos cívicos, os clubes e as associações religiosas; e associações terciárias - grupos de interesses e profissionais nos quais os membros 
são relativamente anônimos. Tal conceito difere da concepção de associações a partir dos seus contornos legais/burocráticos ou de mercado.

Conforme a democracia associativa, as associações impulsionam a democracia de diversas formas: elas promovem virtudes cívicas, oferecem resistência ao poder centralizador do Estado, fiscalizam o governo, melhoram a qualidade e a igualdade de representação ao possibilitar que mais grupos tenham voz (FUNG, 2003). Em suma, o associativismo é um modelo político que pode ser usado para reformar a governança, tornando-a mais compatível com os valores e interesses de uma cidadania culturalmente diversificada (BADER, 2001; HIRST, 2001; WARREN, 2001).

A teoria propõe que atividades sociais possam ser desenvolvidas pelas associações. O Estado e o mercado deveriam se limitar aos papeis que eles podem desempenhar mais eficazmente, as outras atividades seriam exercidas por associações (BADER, 2001). Dessa forma, o controle sobre os serviços seria devolvido aos seus consumidores, tornando-os mais eficazes, forçando os gestores a compartilharem as decisões com base na consulta daqueles que são diretamente afetados pelas políticas públicas (HIRST, 2001).

Compartilhando essa concepção (ainda que não explicitamente), estudos brasileiros confeccionados durante o pico do crescimento das associações no Brasil (década de 1990) destacaram as contribuições de um tipo de associação - as Organizações Não Governamentais (ONGs) - para a democracia (CARDOSO, 1997; FERNANDES, 1994). Segundo tais interpretações, as ONGs proporcionariam a democratização das relações sociais na medida em que os cidadãos poderiam interferir diretamente nas questões públicas. Nesse sentido, a transmissão da responsabilidade pelos serviços públicos para as ONGs seria a forma mais eficiente e eficaz de aplicar os recursos públicos, considerando que as atividades das Organização Não Governamentais não passariam pela burocracia estatal. E também seriam elas as instituições mais familiarizadas com as necessidades e soluções para os problemas sociais.

Por outro lado, estudos problematizam a atividade das ONGs (MONTAÑO, 2002; SADER, 2002). Em geral, as críticas às ONGs se concentram justamente no fato de que, ao assumirem serviços públicos, tais organizações diminuem a 
responsabilidade estatal (MONTAÑO, 2002; SADER, 2002). Com maior detalhamento, Carlos Montaño (2002) explica que as ONGs atuam de forma localizada, ignorando assim a pauta da universalização dos direitos; de forma temporária, em contraste às ações permanentes; e baseadas no voluntariado, em vez de valorizarem o Estado como lugar da concretização dos direitos. Ademais, a mobilização das ONGs resultaria em ações emergenciais e focalizadas que não resolveriam os problemas sociais, mas sim apenas suas consequências. A aposta desses estudos recai sobre os movimentos sociais, esses sim sujeitos capazes de promoverem transformações mais profundas.

A diversidade das associações é central para a teoria da democracia associativa. O cientista político canadense Warren (2001) afirma que as associações são tão diversas que não é possível analisá-las como uma unidade, mas sim como uma ecologia de associações. Assim, o fato de a associação se dedicar a causas sociais, ao poder ou ao dinheiro faz diferença para sua contribuição ao projeto democrático (WARREN, 2001). Inclusive, alguns tipos de associações podem ameaçar valores democráticos em vez de estabilizá-los (FUNG, 2003). Por isso é essencial que haja atuação estatal para que se estimule a criação de associações que respeitem as normas democráticas igualitárias.

Tais apontamentos são importantes em pelo menos dois sentidos: por demonstrarem a variedade das associações, bem como por evidenciarem que existe relação entre associações e regimes de governo. Nesse sentido, esse tipo de interpretação difere de alguns escritos marcantes sobre o campo associativo no Brasil. Por exemplo, o conhecido conceito de terceiro setor, que tem como ponto de partida uma compartimentalização das instituições. Conforme a clássica definição de Fernandes (1994), as associações públicas que atuam para o bem comum fazem parte do primeiro setor; as empresas privadas que visam ao lucro compõem o segundo; e o terceiro setor é composto pelas associações de origem privada que atuam também em prol do bem comum. No entanto, além de separar as associações do Estado, tal definição atribui ao terceiro setor uma espécie de virtude moral, já que ele teria como atributo diminuir as desigualdades sociais, mas sem interesse lucrativo. 
Em outro sentido, interpretações brasileiras mais recentes apontam justamente a interdependência entre as instituições sociais (ABERS; VON BÜLOW, 2011; LAVALLE; SWAKO, 2015; PISMEL, 2019). Para essa literatura, o Estado e a sociedade civil não estariam separados em nenhum período.

A relação entre decisões políticas e associações já vem sendo trabalhada pela literatura. No Brasil, Lüchmann, Almeida e Taborda (2019) sugerem que a Reforma do Estado promovida na década de 1990 proporcionou subsídios políticos e legais que levaram à criação das associações. Durante o primeiro mandato do expresidente Fernando Henrique Cardoso foi promulgada a lei da publicização (BRASIL, 1998). A lei nº 9.637 de 1998 transfere serviços não exclusivos do Estado, como escolas e hospitais, para o setor público não estatal. A parceria entre o poder público e as organizações civis foi considerada pelo ex-ministro da Administração e Reforma do Estado, Bresser Pereira, como suposta saída para os problemas das políticas públicas estatais, pois as organizações civis estariam livres da burocracia pública e seriam mais próximas da população atendida (BRESSER PEREIRA; GRAU, 1999). Além dessas diretrizes, os governos considerados neoliberais teriam estimulado o crescimento das associações de outras formas. Na explicação famosa de Evelina Dagnino (2004), os defensores da diminuição do papel do Estado nas questões sociais, alinhados ao projeto neoliberal, apropriaram-se dos termos do projeto democratizante, transferindo para o indivíduo e para as ONGs a concretização dos direitos dos cidadãos - papel esse que deveria ser do Estado.

O estímulo ao associativismo teria sido central inclusive nos governos posteriores, ainda que sob outros vieses. Com o governo federal do Partido dos Trabalhadores (PT, de 2003 a meados de 2016), cresceram as Instituições de Participação (IPs), como Conferências de Direitos, impulsionando a organização da sociedade civil (ARAÚJO, 2014; AVRITZER, 2016; NOGUEIRA, 2013; OLIVEIRA, 2016; POGREBINSCHI, 2012; TEIXEIRA, 2013).

Além de apostar no fortalecimento da sociedade civil via IPs, o governo do PT levou diversas lideranças de movimentos para cargos centrais na burocracia federal, promovendo assim o ativismo estatal (ABERS, SERAFIM TATAGIBA, 2014; ABERS VON BÜLOW, 2011; GURZA LAVALLE ET AL. 2019; CARLOS; DOWBOR ALBUQUERQUE, 2017; CAYRES, 2017; PIRES VAZ, 2014). 
Já o atual governo, que tem como presidente Jair Bolsonaro, eleito em 2018, tem sido refratário à participação de associações. Prova disso é a publicação do decreto 9.759/2019, que estabelece diretrizes, regras e limitações para colegiados da administração pública federal, extinguindo todo os colegiados que não tenham sido regulamentados em lei (Brasil, 2019). No conceito de colegiado estão incluídos conselhos, comitês, comissões, grupos, juntas, equipes, mesas, fóruns, salas e qualquer outra denominação dada ao colegiado, geralmente compostos por membros do governo e associações. Ademais, Bolsonaro tem atribuído às ONGs a responsabilidade por desastres ambientais, como os recentes incêndios na Amazônia. Conforme noticiado pelo portal G1, "Bolsonaro diz que ONGs podem estar por trás de queimadas na Amazônia para ‘chamar atenção’ contra o governo” (MAZUI, 2019).

A literatura sobre interações socioestatais (ABERS; SERAFIM; TATAGIBA, 2014; ABERS; VON BÜLOW, 2011; GURZA LAVALLE, et all, 2019; CARLOS, DOWBOR; ALBUQUERQUE, 2017; CAYRES, 2017; PIRES VAZ, 2014; PISMEL, 2019 abriu um campo de estudos sobre as diferentes relações entre Estado e sociedade. Consideramos que o exame dessas relações pode ser auxiliado pela teoria da democracia associativa. Bader (2001), inclusive, chama a atenção para a limitação de outras teorias, que não conseguem captar o fato de que todas as sociedades recentes são complexas combinações de diferentes mecanismos de coordenação (hierarquias estatais e organizacionais, mercados, associações e redes).

O impacto das decisões estatais sobre as associações fica ainda mais evidente na compreensão das mesmas como artefatos, conforme definido por Cohen e Rogers (1995). As associações são artefatos, pois dependem das estruturas econômicas e políticas, dos recursos e das instituições nas quais estão inseridas. Ou seja, as associações não são criações naturais, mas sim dependentes de estruturas, bem como de decisões políticas e econômicas (COHEN; ROGERS, 1995).

Embora a conformação das associações sofra a influência de instituições políticas e econômicas, Cohen e Rogers (1995) sugerem que a formação das associações também é condicionada por fatores exógenos ao Estado, tais como a luta por melhor distribuição de renda. Nesse sentido, é vasta a literatura que explica a proliferação das associações pela capacidade de organização da própria sociedade 
civil. O livro mais famoso no Brasil que segue em tal direção, "Quando novos personagens entram em cena" de Eder Sader (1988), descreve a proliferação e importância da sociedade civil no período da redemocratização brasileira.

\section{O financiamento estatal para as associações sem fins lucrativos no Brasil}

O gráfico 1 mostra os períodos de crescimento das associações sem fins lucrativos em geral e na área ambiental, conforme dados da pesquisa sobre Fundações Privadas e Associações Sem Fins Lucrativos no Brasil (FASFIL) (IBGE, 2012):

Gráfico 1 - Crescimento das associações no Brasil

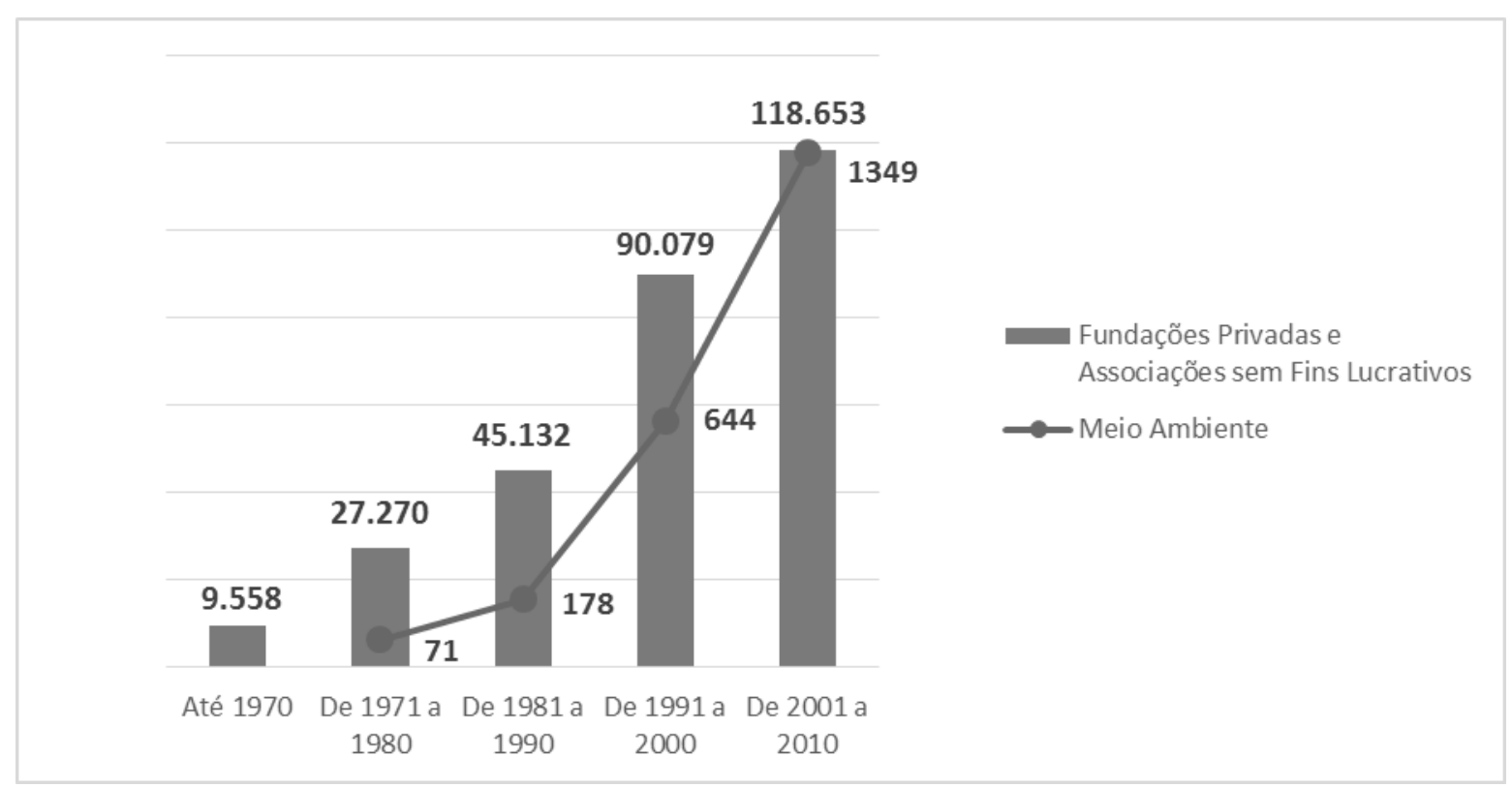

Fonte: Elaborado pela autora, com base nos dados do IBGE (2012).

Conforme dados do gráfico 1, em 1970 existiam 9.558 fundações privadas e associações sem fins lucrativos no Brasil. De 1971 a 1980 elas somavam 27.270. Na década seguinte o número chegou a 45.132. O grande período de crescimento das associações aconteceu entre 1991 e 2000, somando 90.079. Já de 2001 a 2010 existiam 118.653 associações. Nota-se com isso que, em geral, o grande período de crescimento das associações sem fins lucrativos deu-se entre 1991 e 2000, quando 
mais de noventa mil associações foram criadas (quase o dobro da década anterior). O mesmo ocorreu com as associações que atuam com meio ambiente e causa animal: eram 178 entre as décadas de 1981 e 1990, 664 entre as décadas de 1991 e 2000, culminado em 1.349 associações ambientais entre os anos de 2001 a 2010.

É importante contextualizar esses períodos. Nas décadas de 1970 e 1980 o Brasil era comandado por ditadores militares. Só em 1989 os brasileiros voltaram a votar, elegendo Fernando Collor de Mello como presidente. Collor passou por um processo de impeachment em 1992, preferindo renunciar ao cargo. Em seu lugar assumiu o vice, Itamar Franco. Seguiram-se dois mandatos de Fernando Henrique Cardoso (entre 1995 e 2002) responsável pela promoção de políticas neoliberais. Em 2002, Luís Inácio Lula da Silva, filiado ao Partido dos Trabalhadores (PT), foi eleito presidente do país e reeleito em 2006. O PT permaneceu no poder com a eleição de Dilma Rousseff em 2010, também reeleita, em 2104.

O período entre 1991 e 2000 em que o Brasil implementou projetos neoliberais marca o momento em que ocorreram mais repasses de recursos federais para as associações (Ipea, 2011), conforme o gráfico 2 permite observar:

Gráfico 2- Transferência de recursos (em milhões) da União para as entidades sem fins lucrativos de 1999 a 2010

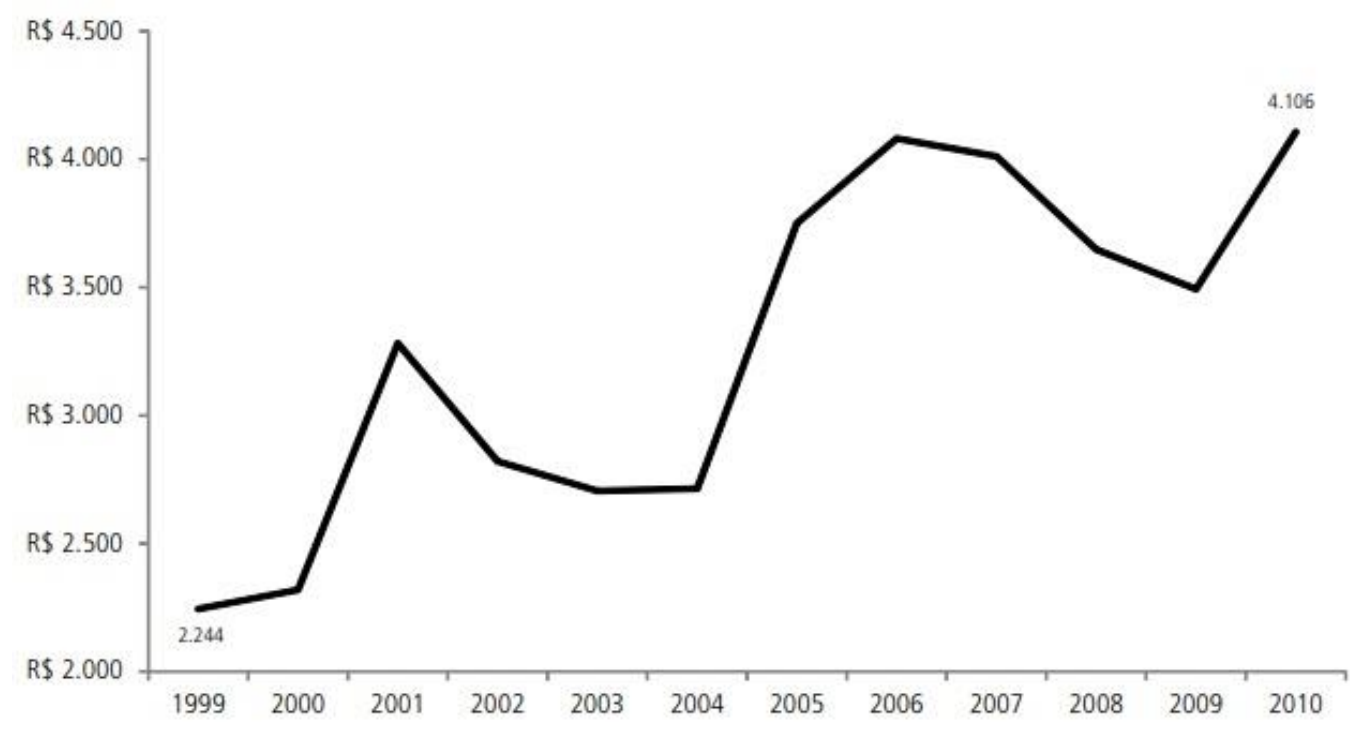

Fonte: Ipea (2011, p.10). 
Conforme dados do gráfico 2, somente em 1999 o governo federal transferiu um pouco mais que dois milhões de reais às organizações. Houve um forte crescimento da transferência de recursos até 2001, quando há uma desaceleração e estagnação até 2004; em seguida o volume de recursos volta a crescer, mantendo-se estável até 2007, quando decai novamente. Em 2010 o repasse de verbas federais para as organizações civis cresce novamente. Os dados de 2010 apontam um total de um pouco mais que quatro milhões destinados pelo governo federal às organizações civis (Ipea, 2011). Dados mais recentes do Ipea (LOPEZ, 2018) apontam queda nesse investimento desde 2014.

O maior pico de investimento nas associações foi em 1999, ano no qual Fernando Henrique Cardoso (FHC) ocupava o cargo da presidência (ele foi presidente entre 1995 e 2002). Como exposto na seção 2, as legislações e ações promovidas durante o governo Fernando Henrique Cardoso determinaram parcerias entre associações e Estado. Por conta desse conjunto de diretrizes há um aumento substancial de transferência de recursos federais para as fundações e associações sem fins lucrativos de 1995 a 2003.

Mas essa não foi uma prática exclusiva ao governo FHC. Durante a gestão de Luiz Inácio Lula da Silva (2003 a 2011), o financiamento federal para as associações e fundações sem fins lucrativos voltou a crescer e permaneceu estável até 2007 , quando decaiu. Especificamente em 2009 o repasse de verbas federais para as associações e fundações sem fins lucrativos cresceu novamente. Os dados de 2010 apontam um total de um pouco mais que quatro milhões destinados pelo governo federal às associações e fundações sem fins lucrativos (IPEA, 2011). Como demonstrado na seção 2, o governo do PT tinha como projeto o fortalecimento da sociedade civil, concretizado especialmente pelo fortalecimento das IPs e do ativismo estatal.

Além de diretrizes políticas da presidência, a ampliação do financiamento estatal para as associações também tem relação com a redução da ajuda internacional. Nas últimas décadas houve redução das fontes de financiamento internacional para as associações sem fins lucrativos brasileiras, em parte devido às dificuldades econômicas nos países financiadores e também pelo fato de que o 
Estado brasileiro, ao aumentar a renda nacional e reduzir a desigualdade social, deixou de figurar entre os destinos prioritários do financiamento internacional direcionado às associações (LOPEZ BUENO, 2012).

No entanto, os repasses federais não são a principal fonte de financiamento das associações. A pesquisa conduzida pelo Centro de Estudos sobre as Tecnologias da Informação e Comunicação (CETIC) ouviu 3.546 associações de todo o país em 2013, incluindo ONGs, sindicatos, igrejas, universidades filantrópicas e outras. Assim revelou-se que $26 \%$ dos recursos das associações provêm de mensalidades e anuidades pagas por associados, outros $24 \%$ advêm de doações voluntárias, ao passo que 24\% das entidades declararam ter nas três esferas de governo seus principais apoiadores. Dentre os financiadores estatais, a principal fonte de recursos públicos são os órgãos municipais, seguidos pelos federais e estaduais (BARBOSA, 2014). No mesmo sentido, na sistematização de dados sobre transferências federais para associações durante o período de 2010 a 2018, Mello, Pereira e Andrade (2019) demonstram que apenas uma parcela minoritária das organizações tem acesso efetivo aos recursos públicos de origem federal.

$\mathrm{Na}$ área ambiental, os repasses públicos parecem ser mais centrais, embora não sejam os únicos. Fossaluza e Tozoni-Reis (2015) pesquisaram 276 ONG ambientalistas no estado de São Paulo. Foram entrevistadas 44 delas e os dados revelaram que tais associações têm como principal financiador o poder público (38,6\%), seguido por outras fontes de financiamento (33,7\% das associações declararam que o orçamento principal advém de festas, vendas de produtos e atividades beneficentes, doações de pessoas físicas e financiamento próprio), enquanto as empresas privadas são as principais financiadoras de $27,7 \%$ das associações.

A despeito desses outros fatores, os dados e reflexões apresentados mostram que o Estado no caso brasileiro é um importante financiador do trabalho das associações e fundações sem fins lucrativos. Isso não significa que a única explicação para o crescimento das associações seria o aumento do financiamento estatal, mas sim que há relação entre as decisões políticas favoráveis ao financiamento das associações e seu aumento. 
Para a compreensão dessa relação cabe retomar as explicações de Cohen e Rogers (1995). Os autores apontam que a formação das associações não é natural, e sim dependente de estruturas econômicas e decisões políticas que estimulem sua criação e atuação - daí o caráter artefatual das associações. No entanto, mais do que constatar essa relação, interessa a essa pesquisa compreendê-la, por isso optou-se por entrevistas qualitativas com membros de associações da área ambiental em Santos/SP.

\section{O surgimento das associações na área socioambiental}

Quando se analisa os relatos a respeito do surgimento e da trajetória das associações que trabalham com a questão ambiental em Santos, é difícil deixar de constatar que suas histórias são parecidas. Das onze associações pesquisadas, nove delas (associações B, C, D, E, F, G, H e K) foram criadas por profissionais com formação em biologia e áreas afins, ou então por praticantes de esportes relacionados ao mar, tais como: mergulhadores (F), pescadores (C), surfistas (H) e fotógrafos (I). Preocupados com a situação da fauna, das praias e das águas da região, esses profissionais resolveram contribuir para a preservação do meio ambiente começando com atitudes menores até montarem a associação da qual ainda fazem parte. Exemplo dessa trajetória está no seguinte trecho da entrevista concedida pela associação F:

somos mergulhadores profissionais e começamos a perceber, na época, que tinha muitos pescadores naquela região e também uma redução visível de espécies marinhas. Queríamos fazer algo para mudar essa situação e decidimos criar a ONG para atuar seriamente nessa área. Começou em 2003, com um pouco de dificuldade nos dois primeiros anos e hoje, com doze anos de atuação, temos muitas colaborações para a pesquisa biológica, repovoamento de espécies marinhas e colaboração na criação de leis de proteção.

Somente duas associações (A e J) distam dos atores e dos motivos que levaram à criação da maioria delas. Nesses casos, o criador da associação A já realizava projetos em outro Estado e começou a atuar na área social em Santos porque mudou para a cidade. A outra associação $(\mathrm{J})$ foi fundada a partir da indignação de um 
empresário com a situação das pessoas em situação de vulnerabilidade social em uma região de mangue. Ambas atuam capacitando comunidades em situação de vulnerabilidade social, oferecendo cursos profissionalizantes.

Os entrevistados citaram o descarte inadequado do lixo, a poluição da água e do mar e o consequente risco à fauna como motivos para participar, criar e manter a associação. É importante ressaltar que esse não é um problema só das últimas duas décadas. Os problemas relacionados ao mar e ao meio ambiente são frequentes na região há muitas décadas - a fundação do Porto de Santos data de 1892.

Há, portanto, fatores exógenos à política estatal relacionados à criação das associações: trata-se da percepção dos entrevistados de que o meio ambiente precisava de interferência dos cidadãos. Mas os fatores relacionados às decisões e oportunidades políticas também aparecem no relato dos entrevistados, reafirmando o caráter artefatual das associações (COHEN; ROGERS, 1995).

Mais detalhadamente, conforme trechos do entrevistado A, o que ocorreu para que sua associação fosse criada foi justamente a oferta de editais e projetos que ofereciam verbas para as associações sem fins lucrativos. Nas palavras do entrevistado: "muitos editais e projetos com empresas rolando, me apoiei nisso. Por isso hoje pretendo investir mais na parte de meio ambiente". O mesmo entrevistado relatou o incentivo que teve de políticos para que criasse uma associação sem fins lucrativos em Santos.

O contexto político e a oferta de editais para associações também foi destacado pelo entrevistado G, que explica que a associação: nasceu em 2003, 2004, com o novo contexto político do Brasil “[...] também pensei que a minha hora era de crescer. Investi, pois achava que com o crescimento do terceiro setor e todo o dinheiro injetado, eu poderia fazer meus projetos crescerem". Mesmo para a associação que ainda não tem financiamento, nem público nem privado, essa possibilidade é importante e por isso "[...] vou semanalmente às audiências públicas pedir uma atenção para nosso projeto" (Associação J).

Esses trechos foram selecionados por ilustrarem a importância do financiamento estatal para esses e outros entrevistados. Logo, a existência dessas associações tem relação com o contexto político. Não por acaso quase todas as associações (dez delas) foram criadas em meados dos anos 2000 (com exceção da 
associação C, que foi criada em 1991 e é mantida pela empresa da família do fundador). Data dessa época a maior política de financiamento das associações sem fins lucrativos pelo poder público.

Esses resultados são importantes porque revelam continuidades na política de financiamento estatal para as associações. Essa era uma das diretrizes do governo Fernando Henrique, evidenciadas pela lei da publicização (Brasil, Lei no 9.637 de 1998). Mas não foi exclusivo de um governo do Partido da Social Democracia Brasileira (PSDB), considerado neoliberal. Houve continuidade nesse financiamento na gestão Lula. Em que pese o PT defender mais o papel do Estado no trato com as questões sociais quando comparado ao PSDB, a prática de financiamento para as associações continuou no governo petista impactando na criação das associações, como as aqui analisadas.

É importante ressaltar que o Estado está presente na medida em que financia o trabalho das associações, permitindo que aquelas existentes sejam mantidas e outras sejam criadas. No entanto, esse incentivo dista de certo comportamento esperado pelos partidos mais à esquerda. Para uma certa concepção, em geral com tradição marxista, quem deve assumir o trato com as questões sociais é o Estado. Ao repassar para as associações, o Estado estaria se eximindo dessa responsabilidade. Essa crítica é muito bem feita por Carlos Montaño (2002) para quem as ONGs atuam de forma localizada, ignorando assim a pauta da universalização dos direitos; de forma temporária, em contraste às ações permanentes; e baseadas no voluntariado, em vez de valorizarem o Estado como lugar da concretização dos direitos.

Quando indagados sobre a mudança de projetos na trajetória das associações, os entrevistados afirmaram que nenhuma organização mudou o foco ao longo dos anos, mas sim ampliaram as atividades e cresceram, inclusive obtendo certificações e títulos como o de Organizações da Sociedade Civil de Interesse público (OSCIP) para poderem firmar convênios com o poder público e com empresas privadas - e de Organização Social (OS) - para gerenciarem equipamentos públicos.

Por exemplo, conforme o entrevistado A: "dois projetos grandes com a Prefeitura de Santos entrarão em vigor agora em 2016, e até por isso, além de sermos OSCIP, temos o título de OS (Organização Social)". Representante significativo do processo de financiamento é a trajetória da organização K. 
Eu morava ali na região e, como bióloga, via o quanto aquela região era precária, tanto pela comunidade, que por falta de conhecimento e estrutura estava praticamente destruindo seu próprio meio ambiente, quanto pelas espécies diversas da fauna e flora que estavam se perdendo. Então decidi fazer algo de concreto, algo de efetivo que também poderia reunir profissionais para unir esforços. Montei a ONG em setembro de 2001, e foi tudo se desenvolvendo como queríamos. Muitas atividades, novas parcerias surgiram com a cessão do terreno para construção da sede, pela União, e fomos crescendo. Para conseguir mais apoios nos tornamos OCIP em 2014.

A importância do apoio governamental pode ser observada pelo exame das fontes de financiamento das associações. Das onze organizações pesquisadas, seis delas se mantêm principalmente com verba pública, sendo que a maior parte provém do estabelecimento de convênios com a prefeitura (A, D e K); duas recebem verbas de instituição estadual ( $\mathrm{F} \mathrm{e} \mathrm{G}$ ) e uma de órgão federal (E). Outras duas organizações criadas recentemente (B e H) contam apenas com verbas vindas de voluntários, mas estão pleiteando repasse da prefeitura. Essas duas últimas organizações destacaram a preocupação com a continuidade de suas atividades caso não obtenham tal financiamento, pois não conseguiriam manter as atividades sem a verba pública.

O setor privado também é responsável pelo surgimento e manutenção de organizações de natureza socioambiental, embora contribua menos que o poder público. No entanto, mesmo as organizações que recebem principalmente verbas públicas contam também com a contribuição da inciativa privada, como as organizações A D e F. Apenas uma organização (C) é totalmente financiada por uma empresa privada e foi criada justamente pelo filho do dono da empresa. Somente duas organizações (I e J) são autossustentáveis. Uma delas comercializa produtos artísticos e cobra por cursos e palestras (I), enquanto outra mantém uma cooperativa de catadores de lixo (organização J).

Esses relatos evidenciam novamente a importância do financiamento, especificamente o estatal, para que a organização possa existir e expandir suas atividades. O Estado quando incentiva empresas privadas a doarem para associações, por meio de benefícios fiscais, também estimula o crescimento das mesmas.

É importante notar que não houve uma catástrofe ou um acirramento de problemas socioambientais em Santos que levasse ao surgimento de organizações 
civis. Houve uma preocupação de profissionais da área que criaram suas organizações tendo vista a possibilidade de continuidade do trabalho das mesmas por meio do financiamento estatal.

A influência do Estado nas associações é destacada pela literatura da democracia associativa, segundo a qual a presença e a qualidade das associações variam de acordo com o desenho institucional, as oportunidades e incentivos estatais, de modo que seu formato e seu funcionamento se modificam a depender das escolhas políticas. No caso brasileiro, o Estado, ao financiar o trabalho das associações, incentiva sua criação, o que evidencia o papel central das decisões políticas na criação das associações, como descrevem Cohen e Rogers (1995).

Quanto à relação com o Estado, dez entrevistados responderam que dialogam com o poder público, cobrando ações e estabelecendo parcerias. Somente a organização J afirmou não possuir relação com governos. Esses dados apontam para a diversidade de relações travadas entre associações e Estado, como apontado pelos estudos brasileiros (ABERS; SERAFIM; TATAGIBA, 2014; CARLOS; DOWBOR; ALBUQUERQUE, 2017). Mas essa relação foi observada em 2015 e 206 quando as entrevistas foram feitas. Depois da ascensão do projeto representado por Bolsonaro, o contexto é outro. Ademais o diálogo apontado pelos entrevistados ocorria com a administração municipal. O governo federal atual tem afastado essa interlocução.

Um dos trechos da entrevista revela mudanças no governo federal e, consequentemente, nos planos das associações. Conforme relatou o entrevistado A, o objetivo para 2016 era crescer mais, mas "Este ano [2016] foi muito parado, pois os recursos diminuíram ou não foram repassados” (organização A). O entrevistado se refere ao ano de 2016, marcado pela instabilidade política. Depois de quase quatorze anos de governo do PT (de 2003 a 2010 com Luiz Inácio Lula da Silva e de 2011 a meados de 2016 com Dilma Rousseff), em 2016, antes de concluir seu segundo mandato, Dilma Rousseff foi destituída do cargo. No seu lugar assumiu o vicepresidente de Dilma, Michel Temer (do Partido do Movimento Democrático Brasileiro, PMDB, depois nomeado Movimento Democrático Brasileiro, MDB, partido à direita no espectro político), já indicando a ascensão do projeto autoritário que no próximo pleito elegeria Jair Bolsonaro como presidente. O governo de Bolsonaro tem se guiado por medidas autoritárias e refratárias à participação social. 


\section{Conclusão}

A presente pesquisa abordou o surgimento das associações que atuam com a questão ambiental no município de Santos/SP, adotando como referencial teórico a democracia associativa. Os resultados indicam que as associações não surgem apenas pela movimentação do campo associativo a despeito das orientações estatais. A decisão de formar associações, conforme as entrevistas realizadas entre os anos de 2015 e 2016, está ligada a um sentimento de que algo precisa ser feito na área ambiental. Mas, para que as mesmas sejam formadas e para que seus trabalhos tenham continuidade, o financiamento estatal foi fundamental. $\mathrm{O}$ financiamento estatal para as associações foi forte tanto no governo de Fernando Henrique Cardoso, quanto nos governos petistas. Hoje o Brasil se encontra sob a administração federal de Jair Bolsonaro, crítico das ONGs.

A pesquisa contribui com a área de estudos nos seguintes aspectos: os dados revelaram a importância das estruturas e decisões políticas e econômicas na conformação das associações. No entanto, fatores relacionados à percepção de problemas ambientais também estão envolvidos em sua criação.

Os resultados trazem implicações para aqueles que trabalham ou estudam associações, na medida em que ressaltam o papel das decisões políticas na trama associativa. Se existe uma aposta na mobilização da sociedade civil, é importante considerar que as mesmas podem ser incentivadas pelo Estado.

Um dos limites da pesquisa tem relação com a escolha das associações ambientais como objetos de reflexão. Essas têm características próprias, que impossibilitam a generalização dos resultados para todo o campo associativo. As associações nas áreas de saúde, por exemplo, ganharam força no período da redemocratização, o que não ocorreu na mesma medida no caso das ambientalistas. A própria diversidade do campo das associações dificulta generalizá-las.

Para futuras pesquisas, sugerimos mais estudos sobre o impacto da orientação estatal nas associações, além da sondagem de sua influência sobre o Estado. Sugere-se também a consulta dos dados quantitativos disponíveis hoje, a 
Revista Brasileira de História \& Ciências Sociais - RBHCS

Vol. $12 \mathrm{~N}^{\circ} 23$, Janeiro - Junho de 2020

exemplo do Mapa das Organizações da Sociedade Civil do Brasil, plataforma digital organizada pelo Instituto de Pesquisa Econômica Aplicada (Ipea) em 2017.

\section{Referências}

ABERS, R.; SERAFIM, L.; TATAGIBA, L. Repertórios de interação EstadoSociedade em um Estado heterogêneo: a experiência na era Lula. Dados, v. 2, p. 325-357, 2014.

ABERS, R.; VON BÜLOW, M. Movimentos sociais na teoria e na prática: como estudar o ativismo através da fronteira entre Estado e sociedade? Sociologias, Porto Alegre, n. 28, p.52-84, 2011.

ALONSO, A.; COSTA, V. Por uma Sociologia dos conflitos ambientais no Brasil. In: Encontro do grupo meio ambiente e desenvolvimento da CLACSO, 2000, Rio de Janeiro. Anais... Rio de Janeiro: CLACSO, 2002. p. 115-137.

ARAÚJO, C. Participação política e gênero: algumas tendências analíticas recentes'. Revista Brasileira de Informação Bibliográfica em Ciências Sociais (BIB), v. 52, p. 45-77, 2001.

AVRITZER, L. Modelos de deliberação democrática: uma análise do orçamento participativo no Brasil. In Santos, B. (org). Democratizar a democracia: os caminhos da democracia participativa. Rio de Janeiro, RJ: Civilização Brasileira, 2002.

BADER, V. Introduction, Critical Review of International. Social and Political Philosophy, v. 4, p. 1-14, 2001.

BARBOSA, A. TIC. Organizações Sem Fins Lucrativos 2012: pesquisa sobre o uso das tecnologias de informação e comunicação em organizações sem fins lucrativos brasileiras. São Paulo: Comitê Gestor da Internet no Brasil, 2014. Disponível em: < http://cetic.br/media/docs/publicacoes/2/TIC\%20OSFIL\%202012\%20\%E2\%80\% 93\%20Livro\%20Eletronico.pdf $>$. Acesso em abril de 2019.

BARDIN, L. Análise de conteúdo. Lisboa: Edições 70, 2006.

BRASIL. Lei n o 9.637, de 15 de maio de 1998. Dispõe sobre a qualificação de entidades como organizações sociais, a criação do Programa Nacional de

Publicização, a extinção dos órgãos e entidades que menciona e a absorção de suas atividades por organizações sociais, e dá outras providências. Coleção de Leis da República Federativa do Brasil, Brasília, 1998.

BRASIL. Decreto no 9.759 de 11 de abril de 2019. Brasília: Presidência da República, 2019.

BRESSER PEREIRA, L. C.; GRAU, N. C. Entre o estado e o mercado: o público não-estatal (orgs.). In: BRESSER PEREIRA, L. C.; GRAU, N. C. O público não estatal na reforma do Estado. Rio de Janeiro: Fundação Getúlio Vargas, 1999, p. 15-48. 
CARDOSO, R. Fortalecimento da sociedade civil. In: IOSCHPE, E. (org.). $\mathbf{3}^{\mathbf{0}}$ Setor: desenvolvimento nacional sustentado. Rio de Janeiro: Paz e Terra, 1997, p.07-12.

CARLOS, E., DOWBOR, M., ALBUQUERQUE, M.C. Movimentos sociais e seus efeitos nas políticas públicas: balanço do debate e proposições analíticas. Civitas: Revista de Ciências sociais, n.17, p. 360-378, 2017. CAYRES. D. C. Ativismo institucional e interações Estado-movimentos sociais.Revista Brasileira de Informação Bibliográfica em Ciências Sociais (BIB), v. 82, p. 81-104, 2017. COHEN, J.; ROGERS, J. Associations and democracy. London, 1995.

COSTA, M. Análise de colaborações entre governo e ONGs e da densidade de ONGs no Brasil. Revista de Administração Pública, n. 51, p.330-347, 2017.

DAGNINO, E. ¿Sociedade civil, participação e cidadania: do que estamos falando? In: MATO, D. Políticas de Ciudadanía y Sociedad Civil in Tiempos de globalización. Caracas, Venezuela: FaCES, Universidad Central de Venezuela, 2004. p. 95-110.

DOIMO, A. M. A vez e a voz do popular: movimentos sociais e participação política no Brasil pós-70. Rio de Janeiro, RJ: Relume/Dumará,, 1995.

FERNANDES, R. Privado porém público: o terceiro setor na América Latina. Rio de Janeiro: Relume/Dumará, 1994.

FOLHA DE SÃO PAULO. Em Santos, 180 homens trabalham para conter fogo em tanques. Notícia publicada em 03/04/2015. Disponível em: <http://www1.folha.uol.com.br/cotidiano/2015/04/1612137-em-Santos-180homens-trabalham-para-conter-fogo-em-tanques.shtml >. Acesso em: jan. 2019a.

FOLHA DE SÃO PAULO. Bombeiros controlam fogo, mas fumaça continua em Guarujá (SP). Notícia publicada em 15/01/2016. Disponível em: <http://www1.folha.uol.com.br/cotidiano/2016/01/1729812-bombeiroscontrolam-fogo-mas-fumaca-continua-em-guaruja-sp.shtml >. Acesso em: jan. 2019b.

FOSSALUZA, A. S.; TOZONI-REIS, M. F. O financiamento das ONGs ambientalistas e sua influência nas ações em educação ambienta. EPEA - Encontro Pesquisa em Educação Ambiental, 2015, Rio de Janeiro. Anais... Rio de Janeiro: EPEA, 2002, p. 01-15.

FUNG, A. Associations and Democracy: Between Theories, Hopes, and Realities. Annual Review of Sociology, California, v. 29, p. 515-539, 2003.

GURZA LAVALLE, A.; CARLOS, E.; DOWBOR, M.; SZWAKO, J. Movimentos sociais, institucionalização e domínios de agência. In: Gurza Lavalle et. al. Movimentos sociais e institucionalização: políticas sociais, raça e gênero no Brasil. RJ: UERJ, 2019.

HIRST, P. Can Associationalism Come Back? Critical Review of International Social and Political Philosophy, London, 4:1, p. 15-30, 2001. 
INSTITUTO BRASILEIRO DE GEOGRAFIA E ESTATÍSTICA (IBGE). Fundações Privadas e Associações sem Fins Lucrativos no Brasil 2010. Estudos e Pesquisas Informação Econômica, v. 20. Rio de Janeiro, RJ: IBGE, 2012.

INSTITUTO DE PESQUISA ECONÔMICA APLICADA (Ipea). Mapa das Organizações da Sociedade Civil. Brasília: Ipea, 2017.

INSTITUTO DE PESQUISA ECONÔMICA APLICADA (Ipea). Transferências federais a entidades privadas sem fins lucrativos: (1999-2010).

Comunicado Ipea, n. 123. Brasília, Ipea, 2011.

LAVALLE, A. G. e SWAKO, J. Sociedade civil, Estado e autonomia: argumentos, contra-argumentos e avanços no debate. Opinião Pública, Campinas, vol. 21, $\mathrm{n}^{\mathrm{o}}$ 1, p. 157-187, 2015.

LOPEZ, F. G. (Org.). Perfil das organizações da sociedade civil no Brasil. Brasília: Ipea, 2018.

LOPEZ, F. G.; BUENO, N. S. Transferências Federais a Entidades Privadas Sem Fins Lucrativos (1999-2010). Texto para discussão. Instituto de Pesquisa Econômica Aplicada Brasília: Rio de Janeiro: Ipea, 2012.

LÜCHMANN, L. H. H. Modelos contemporâneos de democracia e o papel das associações. Revista de Sociologia e Política, Paraná, v. 20, n. 43, p. 59-80, 2012.

LÜCHMANN, L. H. H. Abordagens teóricas sobre o associativismo e seus efeitos democráticos. Revista Brasileira de Ciências Sociais, n. 29, p. 159-178,(2014.

LÜCHMANN, L. H. H; SCHAEFER, M. I.; NICOLETTI, A. SAssociativismo e repertórios de ação político-institucional. Opinião Pública, v. 23, p. 361-396, 2017.

LÜCHMANN, L. H.; ALMEIDA, C.; TABORDA, L. Associativismo no Brasil contemporâneo: dimensões institucionais e individuais. Revista Política e Sociedade, n. 17, p. 307-341, 2019.

MAZUI, G. Bolsonaro diz que ONGs podem estar por trás de queimadas na Amazônia para 'chamar atenção' contra o governo. Reportagem publicada no portal G1 no dia 21/o8/2019. Disponível em:

<https://g1.globo.com/politica/noticia/2019/o8/21/bolsonaro-diz-que-ongspodem-estar-por-tras-de-queimadas-na-amazonia-para-chamar-atencao-contra-ogoverno.ghtml>. Acesso em 20 fev. 2019.

MELLO, J.; PEREIRA, A.; ANDRADE, P. Afinal, o que os dados mostram sobre a atuação das ONGs? Análise das transferências federais e dos projetos executados pelas OSCs no Brasil. Rio de Janeiro, RJ: Ipea, 2019.

MENDONÇA, P., MEDEIROS, A.; ARAÚJO, E. Modelos para parcerias entre governos e organizações da sociedade civil: análise comparativa de políticas de AIDS, assistência social e cultura no Brasil. Revista de Administração

Pública, n. 53(5), p. 802-820, 2019. 
MONTAÑO, C. Terceiro Setor e Questão Social: crítica ao padrão emergente de intervenção social. São Paulo: Cortez, 2002.

NOGUEIRA, T. S. Movimento Feminista e Estado: aproximações e afastamentos a partir do debate sobre a ilegalidade do aborto. Santa Catarina, SC: Universidade Federal de Santa Catarina, 2013.

OLIVEIRA, A. A. O impacto das conferências de políticas para as mulheres nas atividades do legislativo federal. Uberlândia, MG: Universidade Federal de Uberlândia, 2016.

PISMEL, A. Participação, movimentos sociais e políticas públicas: a sistematização inicial de uma agenda de pesquisa. Revista Brasileira de Políticas Públicas e Internacionais, n. 4, p. 9-31, 2019.

PIRES, R. C.; VAZ, A. C. Para além da participação: interfaces socioestatais no governo federal. Lua Nova, v. 93, p. 61-91, 2014.

POGREBINSCHI, T. Conferências nacionais e políticas públicas para grupos minoritários. Texto para Discussão, Instituto de Pesquisa Econômica Aplicada (Ipea), n. 1741, p. 7-45, 2012. SADER, E. Quando novos personagens entram em cena: experiências, falas e lutas dos trabalhadores da Grande São Paulo (1970-80). Rio de Janeiro, RJ: Paz e Terra, 1988.

SADER, E. Para outras democracias. IN: SANTOS, B. S. (org.). Democratizar a democracia: os caminhos da democracia participativa. Rio de Janeiro: Civilização Brasileira, 2002, p.649-679.

SILVA, G. M. História do conceito de desenvolvimento e a ascensão das associações civis. In: XXXV Encontro da Associação Nacional de Cursos de Pós-Graduação em Administração -, 2011, Rio de Janeiro. Anais... Rio de Janeiro: ENANPAD, 2011. p. 01-17.

TOCQUEVILlE, A. A democracia na América Latina. São Paulo: Martins Fontes, [1835] 2005.

WARREN, M. Democracy and Association. Princeton: Princeton University, 2001. 